\title{
A six year review of hysterectomy for benign gynaecological conditions at the Federal Medical Centre, Owerri
}

\author{
Duke A. Onyeabochukwu, Chukwunonyerem Duke-Onyeabo, Onyema A. Onyegbule*, \\ Cornelius C. Amajuoyi, Primus I. Madu
}

Department of Obstetrics and Gynaecology, Federal Medical Centre, Owerri, Imo State, South East Nigeria

Received: 18 March 2014

Accepted: 2 April 2014

*Correspondence:

Dr. Onyema A. Onyegbule,

E-mail: onyemath@gmail.com

(C) 2014 Onyeabochukwu DA et al. This is an open-access article distributed under the terms of the Creative Commons Attribution Non-Commercial License, which permits unrestricted non-commercial use, distribution, and reproduction in any medium, provided the original work is properly cited.

\begin{abstract}
Background: Hysterectomy is one of the commonest major gynaecological surgeries performed for both benign and malignant conditions. Hysterectomy for benign gynaecological conditions is usually done to improve the quality of life of women who suffer from these disorders. Aim of current study was to analyze hysterectomies performed in the centre for benign gynaecological conditions during the period of the study.

Methods: This was a retrospective descriptive study of all cases of hysterectomy (for benign gynaecological disorders over a 6 year period (January 1, 2006 - December 31, 2011) at Federal Medical Centre, Owerri. Information on socio-demographic characteristics, clinical presentation, indication for surgery, type of hysterectomy, operative findings, and postoperative complications during admission were retrieved and analyzed.

Results: Hysterectomy for benign gynecological conditions accounted for $14.1 \%$ of all major gynecological surgeries. The leading indications for hysterectomy were uterovaginal prolapse (47.3\%), uterine fibroid (33.6\%), and dysfunctional uterine bleeding (DUB) (9.1\%). Abdominal hysterectomy accounted for 55.0\% while vaginal hysterectomy accounted for $45.0 \%$ of hysterectomies performed for benign gynecological conditions. A postoperative morbidity rate of $23.7 \%$ was found. Post-operative fever, requiring investigation and treatment, was the leading complication. No mortality associated with hysterectomy was recorded.

Conclusions: Hysterectomy for benign gynaecological conditions is relatively common and safe in our centre, but there is need for improvement on the high post-operative morbidity rate.
\end{abstract}

Keywords: Hysterectomy, Benign, Gynaecology, Owerri

\section{INTRODUCTION}

Hysterectomy which is the complete removal of the uterus is one of the most frequently performed major gynaecological procedures both for benign and malignant conditions of the uterus. ${ }^{1-3}$ Hysterectomy for benign gynaecological conditions are usually undertaken to improve the quality of life of affected women. ${ }^{4-5}$ Hysterectomy may be completed using abdominal, vaginal or laparoscopic approach, and the choice of which approach is influenced by many factors. ${ }^{1,5}$ Some of the benign conditions for which hysterectomy can be performed include uterine leiomyoma, uterovaginal prolapse, menstrual disorders, cervical intraepithelial neoplasm, endometrial or cervical polyps, chronic pelvic pain and adenomyosis. ${ }^{1,3,5}$

The incidence of hysterectomy varies from country to country. In the developed countries, the incidence is high and increasing. In the United Kingdom, it is estimated that about $20 \%$ of the women would have undergone hysterectomy by the age of 50years mainly for menstrual disorders and uterine fibroids. ${ }^{6,7}$ In the United States of 
America, hysterectomy is the second most frequently performed surgical procedure after Caesarean section and it is estimated that at least one in three women would have had a hysterectomy before the age of 60 years. ${ }^{8}$ In developing countries, like ours, most women would reject hysterectomy for fear of surgery, loss of feminity and concerns about future fertility after reincarnation. ${ }^{9}$ In a separate studies in the University of Nigeria Teaching Hospital, Enugu and the University College Hospital, Ibadan, hysterectomy accounted for $14 \%$ and $10.2 \%$ respectively, of all major gynaecological operations. ${ }^{9,10}$

Hysterectomy may be accomplished using different approach as noted earlier and the choice of which to use depends on a number of clinical factors and the expertise of the surgeon. ${ }^{1,11}$ Abdominal hysterectomy allows the greatest ability to manipulate pelvic organs and is preferred if large pelvic organs or extensive adhesions are anticipated. It also offers good access to the ovaries if oophorectomy is desired. However, abdominal hysterectomy is associated with longer patient recovery and long hospital stay, greater risk of postoperative fever, and wound infection when compared to vaginal hysterectomy. ${ }^{11}$

Supra-cervical hysterectomy (or subtotal hysterectomy) was thought to have advantage over Total Abdominal Hysterectomy (TAH) in improving urinary symptoms and preservation of sexual function. This tilted the balance in favour of subtotal hysterectomy in the 1990s. ${ }^{12,13}$ However, randomized studies have shown that abdominal supra-cervical hysterectomy offers no distinct advantages over TAH and in fact there is the risk of cervical cancer and persistent bleeding following supra-cervical hysterectomy. ${ }^{14,15}$ Total abdominal hysterectomy and vaginal hysterectomy tend to be the most commonly performed procedures for benign gynaecological conditions in Nigeria. ${ }^{9,16,17}$ These are usually done for multiparous women between their $4^{\text {th }}$ and $6^{\text {th }}$ decades of life ${ }^{16-18}$ Complications of hysterectomy include injury to the urinary system (ureter and bladder), postoperative fever, urinary tract infection, wound infection, pelvic haematoma or infection, injury to the bowel among others. $^{1,18-19}$

In our environment, hysterectomy is one the most commonly performed procedures and remains an effective and safe intervention for many women with a variety of benign gynaecological disorders. This study was carried out to determine the prevalence among other major gynaecological operations, patients' demographic parameters, indications, postoperative morbidity, and the type of procedure performed in our centre.

\section{METHODS}

This was a retrospective descriptive study of all cases of hysterectomy (both abdominal and vaginal) for benign gynecological conditions over a 6 year period (January 1, 2006 - December 31, 2011) in the Federal Medical
Centre, Owerri. The ethical approval of this work was obtained from the ethical committee of Federal Medical Centre, Owerri. The Federal Medical Centre, Owerri is a 500 bed tertiary hospital serving as a referral centre for four contiguous states of the federation including Imo, Abia, Anambra, and Rivers States. It also serves as a residency training centre in various disciplines of medicine. It is located in Owerri, the capital of Imo State in the South East geopolitical zone. The total number of all major gynaecological operations and the hospital numbers of women that had hysterectomy for benign conditions were retrieved from the theatre operation registers. The hospital numbers were used to trace the case notes of the patients from the hospital record department. Information on socio-demographic characteristics, clinical presentation, and indication for surgery, type of hysterectomy, operative findings, and post-operative complications during admission and at follow up of each patient were retrieved and analyzed. Descriptive statistics was done with SPSS software for windows version 17.0 (SPSS Inc., Chicago, IL).

\section{RESULTS}

The total number of major gynaecological operations performed during the 6 year period was 931, out of which 131 were hysterectomies for benign gynaecological conditions, which amounts to $14.1 \%$ of major gynaecological surgeries. Hysterectomy was the third commonest major gynaecological operation behind abdominal myomectomy (48.5\%) and salpingectomy (17.4\%). The socio-demographic characteristics as shown in table 1 revealed that the majority of women who had hysterectomy were in their $5^{\text {th }}$ to $6^{\text {th }}$ decades of life. The mean age was $50.1 \pm 15.6$ years with a range of $30-75$ years. The majority $66(50.4 \%)$ were grand-multipara, while only 1 person $(0.8 \%)$ was a nullipara who had hysterectomy for endometrial hyperplasia. The indications for and types of hysterectomy are shown in table 3 . The leading indications for hysterectomy were uterovaginal prolapse, $62(47.3 \%)$, while uterine fibroid with or without heavy menstrual bleeding was the second most common 44 (33.6\%). Other indications include dysfunctional uterine bleeding $12(9.1 \%)$, endometrial hyperplasia $5(3.8 \%)$, cervical intra-epithelial neoplasia 4 $(3.1 \%)$ and others such as chronic pelvic pain, adenomyosis etc. Most of the women, 72 (55.0\%) had abdominal hysterectomy, while 59 (45.0\%) had vaginal hysterectomy. Among those who had abdominal hysterectomy, 22 (30.6\%), had hysterectomy with bilateral salpingo-oophorectomy, 38 (52.8\%) had total hysterectomy without oophorectomy while 12 (16.6\%) were subtotal hysterectomies.

The uterine size was clinically adjudged to be normal in $35(26.7 \%)$ cases, while in $40(30.5 \%)$ cases the uterine size was found to be slightly larger than normal but less than 12 weeks. Nearly half, $46(35.1 \%)$ had intraoperative finding of uterine size between 12 to 24 weeks, while only $10(7.7 \%)$ cases had uterine size greater than 
24 weeks size. Elongated uterine cervix with or without pelvic wall prolapse was seen in $53(40.5 \%)$ cases, while uterine leiomyoma with or without adhesions was found in $51(38.9 \%)$ of cases. No gross pathology was found intra-operatively in $15(11.4 \%)$ cases while uni-or bilateral ovarian cyst was found in $9.2 \%$ of cases. There were 31 patients with recorded post-operative complications giving a post-operative morbidity rate of 23.7\%. Postoperative fever $(71.0 \%)$ was the leading complication. Wound infection $(19.4 \%)$ was the second most common post-operative complication, while only one patient $(3.2 \%)$ each had wound dehiscence, bladder and ureteric injury. A large proportion (80.2\%) of the patients stayed in the hospital for 5-7 days, while $19.8 \%$ stayed beyond 7 days as a result of postoperative complication. There was no recorded death among patients in the study population.

Table 1: Socio-demographic characteristics of women who had hysterectomy for benign conditions at the study centre.

\begin{tabular}{|ll|}
\hline Characteristics & $\begin{array}{l}\text { Number of } \\
\text { patients }(\%)\end{array}$ \\
\hline Age (years) & \\
\hline $30-39$ & $13(9.9)$ \\
\hline $40-49$ & $58(44.3)$ \\
\hline $50-59$ & $38(29.0)$ \\
\hline $60-69$ & $16(12.2)$ \\
\hline$\geq 70$ & $06(4.6)$ \\
\hline Total & $131(100)$ \\
\hline Parity & \\
\hline 0 & $1(0.8)$ \\
\hline $1-2$ & $24(18.3)$ \\
\hline $3-4$ & $40(30.5)$ \\
\hline$\geq 5$ & $66(50.4)$ \\
\hline Total & $131(100)$ \\
\hline
\end{tabular}

Table 2: Indications and type of hysterectomy for the period under study.

\begin{tabular}{|ll|}
\hline Indication & $\begin{array}{l}\text { Number of } \\
\text { patients }(\%)\end{array}$ \\
\hline Uterovaginal prolapse & $62(47.3)$ \\
\hline Uterine fibroid \pm heavy menstrual bleeding & $44(33.6)$ \\
\hline Dysfunctional uterine bleeding & $12(9.1)$ \\
\hline Endometrial hyperplasia & $5(3.8)$ \\
\hline Cervical intraepithelial neoplasia & $4(3.1)$ \\
\hline $\begin{array}{l}\text { Others } \\
\text { (e.g. chronic pelvic pain, adenomyosis etc.) }\end{array}$ & $4(3.1)$ \\
\hline Total & $131(100)$ \\
\hline Type of hysterectomy & \\
\hline TAH \pm BSO & $22(16.8)$ \\
\hline TAH only & $38(29.0)$ \\
\hline Vaginal hysterectomy \pm pelvic floor repair & $59(45.0)$ \\
\hline Subtotal Hysterectomy & $12(9.2)$ \\
\hline Total & $131(100)$ \\
\hline
\end{tabular}

Table 3: Distribution of uterine size and operative findings.

\begin{tabular}{|ll|}
\hline Uterine size (weeks) & $\begin{array}{l}\text { Number of } \\
\text { patients }(\%)\end{array}$ \\
\hline Normal & $35(36.7)$ \\
\hline$<12$ & $40(30.5)$ \\
\hline $12-24$ & $46(35.1)$ \\
\hline$>24$ & $10(7.7)$ \\
\hline Total & $131(100)$ \\
\hline Operative findings & \\
\hline Normal & $15(11.4)$ \\
\hline $\begin{array}{l}\text { Elongated uterine cervix } \pm \\
\text { pelvic wall prolapse }\end{array}$ & $53(40.5)$ \\
\hline Fibroid & $38(29.0)$ \\
\hline Fibroid + adhesion & $13(9.9)$ \\
\hline Ovarian cyst & $12(9.2)$ \\
\hline
\end{tabular}

Table 4: Complications following hysterectomy.

\begin{tabular}{|ll|}
\hline Complications & $\begin{array}{l}\text { Number of } \\
\text { patients }(\%)\end{array}$ \\
\hline Wound infection & $6(19.4)$ \\
\hline Postoperative fever & $22(71.0)$ \\
\hline Wound dehiscence & $1(3.2)$ \\
\hline Bladder injury & $1(3.2)$ \\
\hline Ureteric injury & $1(3.2)$ \\
\hline Total & $31(100)$ \\
\hline
\end{tabular}

\section{DISCUSSION}

Hysterectomy for benign gynaecological conditions accounted for $14.1 \%$ of major gynecological surgeries. This was comparable to the findings in other parts of the country like Kano, Enugu, Jos and Calabar ${ }^{2,9,16,21}$ but higher than the figures from, Gombe, Ibadan, and Uyo. ${ }^{10,21,22}$ The findings that the majority of patients who had hysterectomy were multiparous and in their $5^{\text {th }}$ and $6^{\text {th }}$ decades of life were similar to other published series ${ }^{16,17,20}$ and reflects the socio-cultural background of the population studied. The importance attached to child bearing in our environment may be the reason why hysterectomy rate was low in women with low parity, occurring only in $19.1 \%$ of those that are Para 2 or less, in this study. Only one $(0.8 \%)$ of those who had hysterectomy was a nullipara. This was far lower than the figures from Maiduguri and Calabar where 20\% and $2.9 \%$ respectively, of hysterectomies were in nulliparous women. $^{20,23}$

The leading indication for hysterectomy in this study was uterovaginal prolapse $62(47.3 \%)$ which was closely followed by uterine fibroid $44(33.6 \%)$. This was not in agreement with other findings elsewhere where uterine fibroid was the leading indication for hysterectomy. ${ }^{10,23,24}$ The reason for this may be that even though uterine fibroid was very common, most women with uterine fibroid in our environment would prefer myomectomy to 
hysterectomy in their management as the former conserves the uterus.

Total abdominal hysterectomy accounted for 60 (45.8\%) of the hysterectomies in this study. This was comparable to $42.6 \%$ in other parts of the world ${ }^{25}$, but lower than $75 \%$ and $81.7 \%$ reported in Jos and Gombe. ${ }^{2,21}$ The vaginal hysterectomy rate of $45.0 \%$ in this study was higher than $20.7 \%, 10.6 \%$ and $19.3 \%$ reported in some parts of the country. ${ }^{2,21,23}$ The higher rate of vaginal hysterectomy in this study was because most of the patients presented with uterovaginal prolapse that could safely be removed through the vaginal route. Vaginal hysterectomy has been shown to have less post-operative morbidity and shorter hospital stays than abdominal which was in agreement with the findings of this study. ${ }^{1,23,25}$ It should therefore, be performed more readily whenever feasible.

Supra-cervical (subtotal) hysterectomy was performed in $12(9.2 \%)$ of the cases. This is higher than $4.4 \%$ and $5.8 \%$ reported from Gombe and Maiduguri. ${ }^{21,23}$ Supracervical hysterectomy is faster to do than total abdominal hysterectomy and was also previously thought to protect from bladder and sexual dysfunction. ${ }^{12,13}$ However, recent studies have shown that supra-cervical hysterectomy has no clear advantage over total abdominal or vaginal hysterectomy in terms of urinary symptoms and sexual function. $^{14,15,25}$

The majority of the patients had normal or uterine size less than 12 weeks size $75(57.2 \%)$. This was similar to the findings in Gombe and South Africa where more than half of the patients had uterine size less than 12 weeks, ${ }^{21,26}$ but higher than the findings in Enugu and Ibadan where fewer patients had normal or uterine size less than 12 weeks. ${ }^{9,10}$ Elongated uterine cervix with or without pelvic wall prolapse $53(40.5 \%)$ was the commonest intra-operative finding noted in this study. This was not surprising since the leading cause of hysterectomy was utero- vaginal prolapse. Uterine fibroid was seen in $51(38.9 \%)$ of the patients. Its association with pelvic adhesions was seen in $13(9.9 \%)$ of the cases which is comparable to the findings in similar studies in Gombe and South Africa. ${ }^{21,26}$ The association between uterine fibroid and pelvic adhesions was proposed by some authors, ${ }^{9,10}$ but was disputed by some others. ${ }^{23,28}$

The mean duration of hospital stay was 8.1 days with a range of 5-22 days. This was similar to the 8.3 days reported by Bukar et al. ${ }^{21}$ but lower than the 11.2 days reported by Kawuwa et al. ${ }^{23}$ The crude postoperative morbidity rate of $23.7 \%$ found in this study is comparable to $24.2 \%$ reported in earlier studies in Enugu and Paris but lower than $31.5 \%$ and $32.6 \%$ reported in Gombe and Ethiopia, respectively. ${ }^{21,29}$ Post-operative fever requiring investigations was the leading complication $22(71.0 \%)$ in this study. This was similar to the findings by Ahmed et al. ${ }^{30}$ but different from studies by Bukar et al. and Anzaku et al. ${ }^{2}$ where wound infection was the leading post-operative complication.
There was no mortality in this study as was the case in other studies. $^{2,21}$ This may be a reflection of the safety of the procedure and the high standard of care in our centre.

In conclusion, hysterectomy for benign gynaecological conditions is relatively common and safe in this centre, but there is need for improvement on the high postoperative morbidity rate. The shorter duration of hospital stay and fewer post-operative complications following vaginal hysterectomy has an economic appeal and therefore vaginal hysterectomy should be the preferred route whenever feasible.

\section{Funding: No funding sources}

Conflict of interest: None declared

Ethical approval: The study was approved by the ethics committee of Federal medical centre, Owerri

\section{REFERENCES}

1. Schorge JO. Surgeries for benign gynecological conditions. In: Schorge JO, Schaffer JI, Halvorson LM, Hoffman BL, Bradshaw KD, Cunningham FG, eds. 1st ed. Williams Gynecology. USA: The McGraw- Hill companies; 2008: 866-974.

2. Anzaku AS, Musa J. Total Abdominal Hysterectomy for benign gynecological conditions at a University teaching hospital in Nigerian (Nig). J Med. 2012;21(3):326-30.

3. Wieslander CK, Dandade D, Wheeler JM. Therapeutic gynecological procedures In: Decherney AH, Goodwin TM., Nathan L, Laufer N, eds. Current Diagnosis and Treatment Obstetrics and Gynecology 10th ed. USA: The McGraw-Hill companies; 2007 : 796-818.

4. Gray R. The future of hysterectomy. BJOG. 2005;112:1333-9.

5. Jones HW. Abdominal hysterectomy In: Rock JA, Jones HW, eds. Te Linde's Operative Gynecology 10th ed. Philadelphia, USA: Lippincott Williams and Wilkins; 2008: 727-743.

6. Thakar R, Ayers S, Georgakpolou A, Clarkson P, Stanton S, Manyonda I. Hysterectomy improves quality of life and decreases psychiatric symptoms: a prospective and randomized comparison of total versus subtotal hysterectomy. BJOG. 2004;11:111520.

7. Vassey MP, Villar-Mackintosh L, McPherson K, Coulter A, Yeates D. The epidemic of hysterectomy: findings in a large Cohort study. $\mathrm{Br} \mathrm{J}$ Obstet Gynaecol 1992;99:402-7.

8. Farguhar CM, Steiner CA. Hysterectomy rate in the United States, 1990-1997. Obstet Gynecol. 2002;99:229-34.

9. Onah HE, Ezegwui HU. Elective abdominal hysterectomy: indications and complications in Enugu, Eastern Nigerian. Global J Med Sci. 2002;1:49-53. 
10. Olumuyiwa AR, Okunlola MA. Abdominal hysterectomy for benign gynecological conditions at Ibadan. Trop J Obstet Gynaecol. 2001;18(1):79-84.

11. Johnson N, Barlow D, Lethaby A et al. Methods of hysterectomy: systematic review and meta-analysis of randomized controlled trials. $\mathrm{Br}$ Med $\mathrm{J}$. 2005;330:1478-88.

12. Kilkku P. Supra-vaginal uterine amputation versus total hysterectomy with references to subjective bladder symptoms and incontinence. Acta Obstet Gynaecol Scand. 1985;64:375-9.

13. Baggies MS. Total and subtotal abdominal hysterectomy. Best Pract Res Clin Obsetet Gynaecol. 2005;19:124-30.

14. Kuppermann M, Sunmmit RL Jr, Varner RE et al. Sexual functioning after total compared with supracervical hysterectomy: a randomised trial. Obstet Gynaecol. 2005;105:1309-15.

15. Roussis NP, Waltrous L, Kerr A et al. Sexual response in the patient after hysterectomy: total abdominal versus supra-cervical versus vaginal procedure. Am J Obstet Gynaecol. 2004;186:49-55.

16. Omole-Ohonsi A, Muhammad Z, Lawan UM, Abubakar IS. Elective hysterectomy in Kano. Nig Clin Rev. 2005;9:26-30.

17. Orji EO, Ndukuba VI. Elective hysterectomy in Obafemi Awolowo University teaching hospital complex, ILE- Ife. Sahel Med J. 2002;5:95-8.

18. Shittu OB, Adeyanju OA, Adebayo AS, Okunlola A, Olayemi OO, Obisesan KA. Ureteric injuries arising from obstetric and gynaecologic operations at the university college hospital Ibadan: a 20 year review. Trop J Obstet Gynacol. 2003;20:32-6.

19. Gimbel H. Total or subtotal hysterectomy for benign uterine diseases? A meta-analysis. Acta Obstet Gynecol Scand. 2007;86:113-44.

20. Udoma EJ, John ME, Ekanem AD, Etuk SJ. Hysterectomies among teenagers in Calabar, Nigeria. Trop Doct. 2004;34:110-2.
21. Bukar M, Audu B, Yahaya UR. Hysterectomy for benign gynaecological conditions at Gombe, North Eastern Nigerian. Nig Med J. 2010;35-8.

22. Abasiattai AM, Bassey EA, Umoiyoho AJ. Elective hysterectomy at the University of Uyo teaching hospital: a 3 year review. Nig Hosp Pract. 2009;4:811.

23. Kuwa MB, Mairiga AG, Audu BM. Indications and complications of hysterectomy in Maiduguri, North Eastern Nigeria. Kanem J Med Sci. 2007;1(1):20-5.

24. Aksu F, Gezer A, Oral E. Seventeen-year review of hysterectomy procedures in a University clinic in Istanbul (1985- 2001). Arch Gynecol Obstet. 2004;270(4):217-22.

25. David ME, Rouzier R, Chaperon C, Davai E. Surgical routes and complications of hysterectomy for benign disorders: a prospective observational study in French University hospital. Hum Reprod. 2007;22(1):260-5.

26. Chrysostomu A. Implication of performing laparoscopic assisted vaginal hysterectomy versus abdominal hysterectomy on suitable patients in a South Africa hospital setting. South Africa J Obstet Gynaecol. 2008;14:70-4.

27. Sait K, Alkhattabi M, Boker A, Alhashemi J. Hysterectomy for benign conditions in a University in Saudi Arabic. Ann Saudi Med. 2008;28:282-6.

28. Leung PL, Tsang SW, Yuen PM. An audit on Hysterectomy for benign disease in public hospital in Hong Kong. Hong Kong Med J. 2007;13:187-93.

29. Gaym A. Elective hysterectomy at Tikur Anbessa teaching hospital, Addis Ababa. Ethiop Med J. 2002;40(3):217-6.

30. Ahmed F, Wasti S. Infectious complications following abdominal hysterectomy in Karachi, Pakistan. Int J Gynaecol Obstet. 2001;73:27-34.

DOI: $10.5455 / 2320-1770 . i j r \operatorname{cog} 20140613$

Cite this article as: Onyeabochukwu DA, DukeOnyeabo C, Onyegbule OA, Amajuoyi CC, Madu IP. A six year review of hysterectomy for benign gynaecological conditions at the Federal Medical Centre, Owerri. Int J Reprod Contracept Obstet Gynecol 2014;3:352-6. 